\title{
JENIS - JENIS PANDANUS (Pandanaceae) DI CAGAR ALAM BIAK UTARA KABUPATEN BIAK NUMFOR
}

\section{(Types of Pandanus [Pandanaceae] in Biak Utara Nature Preserve of Biak Numfor District)}

\author{
Markus Obed Kapitarauw ${ }^{1}$, Charlie D. Heatubun ${ }^{1 凶}$ dan Francina F. Kesaulija ${ }^{1}$ \\ Jurusan Kehutanan, Fakultas Kehutanan Universitas Papua Manokwari, Papua Barat, \\ 98314. Tlp/Fax: +62986211065. \\ ${ }^{\square}$ Penulis Korespondensi: Email: c.heatubun@unipa.ac.id \\ Diterima: 16 Apr 2017| Disetujui: 29 Apr 2017
}

\begin{abstract}
Abstrak
Penelitian ini bertujuan untuk mengetahui jenis-jenis pandanus (pandanceae) yang terdapat pada Kawasan Cagar Alam Biak Utara Kabupaten Biak Numfor. Metode yang digunakan dalam penelitian ini adalah metode deskriptif dengan teknik observasi lapang melalui pejelajahan kawasan. Identifikasi karakteristik morfologi dilakukan untuk melihat variasi jenis-jenis pandanus yang ditemukan. Dari hasil penelitian ditemukan 3 jenis pandanus yaitu Pandanus sp. (Answarik), P. kraneulianus K.Sehum (Mansyoi) dan P. papuanus Solms. Laub (Kakof). Secara morfologis, ketiga jenis pandanus sangat berbeda berdasarkan ukuran batang, ukuran daun dan jumlah buah.
\end{abstract}

Kata kunci: Pandanus, cagar alam, karakteristik morfologi, Biak Numfor.

\begin{abstract}
The objective of the study was to reveal types of Pandanus and its characteristics in Biak Utara Nature Preserve area of Biak Nufor District. Method applyied in the study was descriptive through field observation and exploration. Morphological identification of plant characteristics was carried out to determine types of pandanus that have been found. The result pointed out three types of pandanus found: Pandanus sp. (Answarik), P. kraneulianus K.Sehum (Mansyoi) dan P. papuanus Solms. Laub (Kakof). In terms of morphological characteristicts, thoses three pandanus were very different in branch size, leaf size, and number of fruits.
\end{abstract}

Keywords: Pandanus, nature preserve, morphological characteristic, Biak Numfor.

\section{PENDAHULUAN}

Paradigma baru di sektor Kehutanan memandang hutan sebagai suatu sistem sumber daya yang bersifat multi fungsi, multi guna dan memuat multi kepentingan serta pemanfaatannya untuk mewujudkan kemakmuran bagi rakyat. Manfaat tersebut bukan hanya berasal dari hasil hutan kayu yang memberikan sumbangan $20 \%$, melainkan juga manfaat hasil hutan bukan kayu (HHBK) dan jasa lingkungan (pemanfaatan aliran air, pemanfaatan air, wisata alam, perlindungan keanekaragaman hayati) yang memberikan sumbangan terbesar $80 \%$. Namun himgga saat ini Potensi HHBK tersebut belum dapat di manfaatkan secara optimal. Paradigma ini menyadarkan kita bahwa, produk HHBK 
merupakan salah satu sumberdaya hutan yang juga memiliki keunggulan yang paling bersinggungan dengan kehidupan masyarakat di hutan (Kemeray 2013).

HHBK sangat terbukti dapat memberikan dampak yang positif pada penghasilan masyarakat di sekitar hutan dan juga memberikan kontribusi yang berarti bagi penambahan devisa negara serta lebih bernilai dari pada kayu dalam jangka panjang. Salah satu HHBK yang telah lama dimanfaatkan masyarakat adalah tumbuhan Pandanus dari kelompok Pandanceae. Jenis - jenis dari marga Pandanceae merupakan salah satu anggota yang paling luas persebarannya dan tempat yang ditempatinya (Sinaga dkk. 2011). Menurut (Marpaung dkk. 2013) menguraikan bahwa marga Pandanus memiliki anggota sekitar 700 jenis meliputi daerah Sumatera, Jawa, Bali, Kalimantan, Sulawesi, Maluku, dan Papua. Pandanus adalah tumbuhan monokotil termasuk dalam ordo Pandanales dan merupakan famili dari kelompok pandanaceae, memiliki hampir sebanyak 600-700 jenis dan sebanyak 500 jenis terdapat di New Guinea (Stone 1983). Tumbuhan ini tumbuh di pantai pantai daerah tropis, dicirikan dengan daun yang memanjang, tepinya berduri, akarnya besar dan memiliki akar tunjang yang berfungsi menopang tumbuhan ini dan buahnya tersusun dalam karangan berbentuk membulat (Kemeray 2013).

Cagar Alam Biak Utara adalah satusatunya Cagar Alam yang terdapat di Kabupaten Biak Numfor dengan luas wilayah sekitar 6.138,04 ha. Kawasan ini memiliki bentuk topografi perbukitan dan dataran rendah dengan puncak tertinggi (629 dpl). Kawasan Cagar Alam Distrik Biak Utara selain menyimpan berbagai potensi tumbuhan dan hewan juga menjadi lokasi endemik bagi kehidupan satwa yang ada di sekitar areal tersebut (Linda 2012).

Penelitian ini bertujuan untuk mengetahui jenis-jenis pandanus (Pandanceae) yang terdapat pada Kawasan Cagar Alam Biak Utara Kabupaten Biak Numfor. Hasil dari penelitian ini diharapkan dapat menjadi informasi dasar tentang potensi jenis-jenis pandanus di Cagar Alam Biak Utara dan secara umum merupakan informasi bagi Pemerintah Daerah (PEMDA) setempat dan pihak-pihak yang terkait dengan pengolaan dan pemanfaatan Kawasan Cagar Alam di Biak Utara, di masa mendatang serta dapat bermanfaat bagi penelitian-penelitian selanjutnya.

\section{METODE PENELITIAN}

Penelitian ini dilaksanakan di sekitar Cagar Alam Biak Utara Kabupaten Biak Numfor dan Herbarium Pusat Keanekaragaman Hayati (PPKH) Universitas Papua Manokwari dengan objek utama yaitu jenis - jenis Pandanus di Cagar Alam Biak Utara Kabupaten Biak Numfor.

\section{Metodologi Penelitian}

Metode yang digunakan dalam penelitian ini adalah metode deskriptif dengan teknik observasi lapang. Teknik pengumpulan data dilakukan dengan cara pejelajahan pada Kawasan Hutan Cagar Alam Biak Utara untuk mendapatkan data tentang jenis - jenis Pandanus yang terdapat pada Kawasan tersebut.

\section{Prosedur Penelitian}

Sebelum melakukan pengamatan, terlebih dahulu dilakukan orientasi lapangan berdasarkan peta lokasi penelitian untuk melihat kondisi langsung 
di lapangan untuk menentukan daerah daerah jelajah yang dapat mewakili keadaan seluruh luas hutan tersebut. Data yang diperoleh di lapangan berupa ciriciri morfologi, yang dideskripsikan berdasarkan ciri dan karakteritsit tumbuhan. Dalam pembuatan specimen herbarium, jenis pandanus yang ditemukan masing - masing dibuat sebanyak 5 duplikat dan bagian - bagian dari tumbuhan pandanus yang di ambil untuk specimen, diupayakan untuk mewakili tumbuhan tersebut.

\section{Parameter Studi}

Pengamatan ciri morfologi yang meliputi karakteristik tumbuhan antara lain: sifat tumbuh (tunggal, berumpun), tipe dan ukuran tumbuhan apakah besar (tinggi $>10 \mathrm{~m}$ diameter $10 \mathrm{~cm}$ ), sedang (tinggi 3-10 $\mathrm{m}$ dan diameter $5-10 \mathrm{~cm}$ ) dan kecil (tinggi $3 \mathrm{~m}$ dan diameter $<5$ $\mathrm{cm})$. Morfologi akar yang meliputi warna akar, bentuk akar dan keadaan permukaan akar (licin, kasar, berduri, bersisik). Morfologi batang yang meliputi panjang batang $(\mathrm{m})$, diameter batang $(\mathrm{cm})$, bentuk batang (bulat, pipih, persegi), warna batang, tekstur permukaan batang (licin, beralur, berbulu, berduri), dan arah tumbuh (tegak, menggantung, rebah). Morfologi daun meliputi jumlah daun, warna daun bagian atas dan bawah, keadaan permukaan daun (licin, kasar, berkerut, berduri, bersisik, gundul), bentuk ujung daun, panjang dan lebar daun (cm), bentuk daun (Undivided, digitate, pinate, bipinate, palmate), dan bentuk tepi daun. Morfologi bunga yang meliputi bentuk bunga, dan susunan bunga. Serta morfologi buah yang meliputi bentuk dan ukuran buah, tekstur permukaan buah, dan warna buah (waktu mudah dan matang). Selain itu informasi tambahan seperti ketinggian tempat tumbuh, keadaan tempat tumbuh, jenis vegetasi sekitar juga diambil guna mensinkronkan kedalaman informasi dari penelitian ini.

\section{Analisis Data}

Data berupa pengamatan morfologi yang didapat dari lapangan, kemudian dideskripsikan persamaan dan perbedaannya dengan bantuan buku identifikasi Pandanus, kemudian dianalisis secara tabulasi dan disertai dengan gambar jenis - jenis Pandanus.

\section{HASIL DAN PEMBAHASAN}

\section{Jenis - Jenis Pandanus Di Cagar Alam Biak Utara}

Berdasarkan hasil observasi di Cagar Alam Biak Utara Kabupaten Biak Numfor, ditemukan 3 jenis Pandanus. Jenis - jenis Pandanus yang ditemukan pada Kawasan Cagar Alam Biak Utara disajikan dalam Tabel 1. Tabel 1. Jenis-jenis pandanus pada Kawasan Cagar Alam Biak Utara.

\begin{tabular}{lllll}
\hline No. & Sub Famili & Marga & \multicolumn{1}{c}{ Spesies } & Nama Lokal \\
\hline 1. & Pandanaceae & Pandanus & Pandanus sp & Answarik \\
2. & Pandanaceae & Pandanus & P. kraneulianus K.Sehum & Mansyoi \\
3. & Pandanaceae & Pandanus & P. papuanus Solms. Laub & Kakof \\
\hline
\end{tabular}


Hanya ditemukan tiga jenis Pandanus di Cagar Alam Biak Utara. Hal in merujuk pada teori biogeografi pulau yang mana bahwa pulau-pulau kecil memiliki lebih sedikit spesies tumbuhan (jenis vegetasi) dibandingkan pulau pulau besar yang berdekatan dengan daratan yang lebih memiliki spesies yang banyak (Dahruddin dkk. 2005).

Jumlah spesies Pandanus yang ditemukan di Cagar Alam Biak Utara yaitu Pandanus sp. Pandanus kraneulianus. K. Sehum dan Pandanus papuanus Solms. Laub. Bila dibandingkan dengan penelitian Pandanus di kepulauan Roswar juga terdapat tiga jenis pandanus yaitu Pandanus tectorius, Pandanus polycephalus, Pandanus dubius ketiga jenis ini tumbuh pada tempat yang berpasir basah dan dekat pinggir pantai (Kemeray 2013). Perbedaan ketiga jenis pandanus yang tumbuh pada kedua daerah yang berbeda, dan miliki jenis yang beberda pula.

Secara morfologi ketiga jenis pandanus di Cagar Alam Biak Utara sangat berbeda berdasarkan ukuran batang, ukuran daun dan jumlah buah. Ukuran batang Pandanus sp. lebih besar dibandingkan dengan kedua jenis yang lainnya, dimana Pandanus sp. berukuran $15 \mathrm{~cm}$, sedangkan Pandanus kraneulianus K. Sehum dan Pandanus papuanus Solms. Laub sebesar $12-13$ cm. Perbedaan pada daun yaitu pada ukuran panjang dan lebar. Pandanus sp. memiliki ukuran panjang daun $160-170$ $\mathrm{cm}$ dan lebar daun $6-8 \mathrm{~cm}$, jika dibandingkan bandingkan dengan Pandanus kraneulianus K. Sehum yang mimiliki panjang daun $112-117 \mathrm{~cm}$ dan lebar daun 6-9 cm, sementara Pandanus papuanus Solms. Laub memiliki panjang daun $110-130 \mathrm{~cm}$ dan lebar daun $5-6,3$ $\mathrm{cm}$. Jumlah buah pada 1 pohon pandanus berbeda, Pandanus papuanus Solms. Laub memilki $7-8$ buah dalam satu pohon, Pandanus kraneulianus K. Sehum memiliki $1-2$ buah dalam satu pohon, sedangkan pandanus sp tidak ditemukan buah saat penelitian. Berdasarkan karakter morfologi di atas terlihat bahwa Pandanus sp. merupakan pandanus berukuran besar karena, memiliki ukuran batang dan daun yang lebih besar dibandingkan dengan kedua Pandanus papuanus Solms. Laub dan Pandanus kraneulianus K. Sehum yang ditemukan di Kawasan Cagar Alam Biak Utara.

\section{Deskripsi Morfologi Pandanus Pada Cagar Alam Biak Utara}

\section{Pandanus sp.}

\section{Nama Daerah : Answarik}

Perawakan: Pandanus berukuran sedang hingga besar, tumbuh tegak, berumpun hingga tunggal. Akar: Warna akar Cokelat keabu - abuan bentuk akar tunjang, keadaan permukaan akar kasar dan berduri. Batang: batang berbentuk bulat, warna cokelat keabu - abuan, diameter batang $15-18 \mathrm{~cm}$, tinggi pohon 8 meter, tekstur batang kasar dan berduri, bentuk batang bulat, arah tumbuh batang tegak. Daun: bentuk ujung daun meruncing, susunan daun berseling (alternate) pada batang, panjang daun $160-170 \mathrm{~cm}$, lebar daun $6 \mathrm{~cm}$, bentuk tepi daun bawah daun berduri, bentuk daun panjang, warna atas daun hijau mengkilat sedangkan bagian bawah daun berwarna hijau keabu - abuan, jumlah daun 50 - 80 daun. Bunga: tidak ditemukan bunga pada waktu penelitian. Buah: tidak ditemukan buah pada waktu penelitian. Habitat: tumbuh pada tanah rawa sedikit berkapur dengan serasah 
tipis, tumbuh pada ketinggian $318 \mathrm{~m} \mathrm{dpl}$. Berasosiasi dengan Ficus sp., pakis, palem, paku- pakuan dan Zyzigium sp. Distribusi: menyebar di daerah Papua,

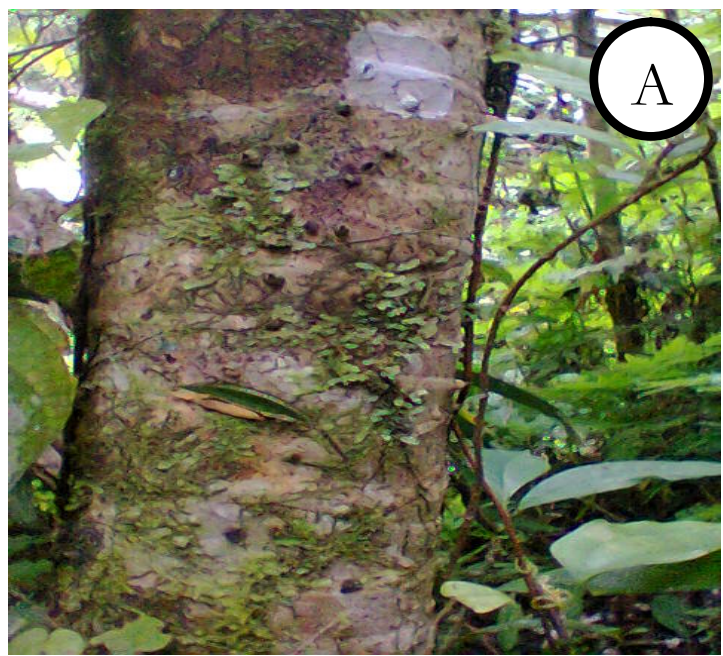

Gambar 1. Pandanus sp. A). Batang utama dan Kawasan Cagar Alam Biak Utara.

\section{Pandanus kraneulianus. K. Sehum Nama Daerah : Mansyoi}

Perawakan: Pandanus berukuran sedang hingga besar, tumbuh tegak, berumpun hingga tungga. Akar: Warna akar cokelat keabu-abuan bentuk akar tunjang, keadaan permukaan akar kasar dan berduri. Batang: batang berbentuk bulat, warna cokelat keabu - abuan, diameter batang $12-15 \mathrm{~cm}$, tekstur batang kasar dan berduri, tinggi pohon 7 - $8 \mathrm{~m}$, bentuk batang bulat dan arah tumbuh batang tegak. Daun: bentuk ujung daun meruncing, susunan daun berseling pada batang, panjang daun 112 - $117 \mathrm{~cm}$, lebar daun $6-9 \mathrm{~cm}$, bentuk tepi dan bawah daun berduri, bentuk daun
Papua New Guinea, termasuk daerah Cagar Alam Biak Utara.

Spesimen acuan : Cagar Alam Biak Utara, 28 April, 2015, MK - 01 .

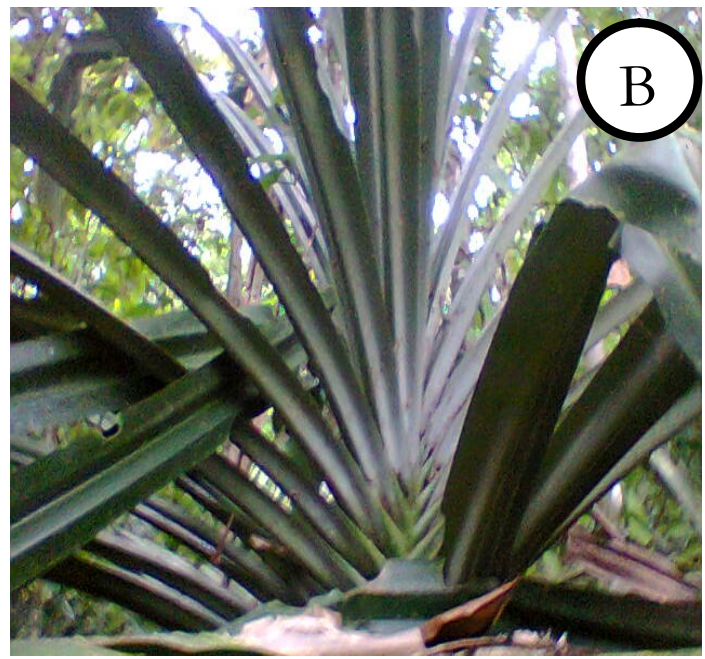

B). Daun Pandanus sp. yang tumbuh di panjang, warna atas daun hijau mengkilat sedangkan bagian bawah daun berwarna hijau keabu - abuan, Jumlah daun 50 - 80 daun; Bunga: tidak ditemukan pada saat penelitian, Buah: buah berbentuk panjang seperti buah merah, warna kuning kehijauan saat mudah dan kuning tuah pada saat matang. Habitat: tumbuh pada tanah rawa sedikit berkapur dengan serasah tipis, tumbuh pada ketinggian 320 m dpl. Berasosiasi dengan Ficus sp., pakis, palem, paku - pakuan dan liana. Distribusi: menyebar di daerah Papua, Papua Nugini, termasuk daerah Cagar Alam Biak Utara.

Spesimen Acuan : Cagar Alam Biak Utara, 29 April, 2015, MK - 02. 


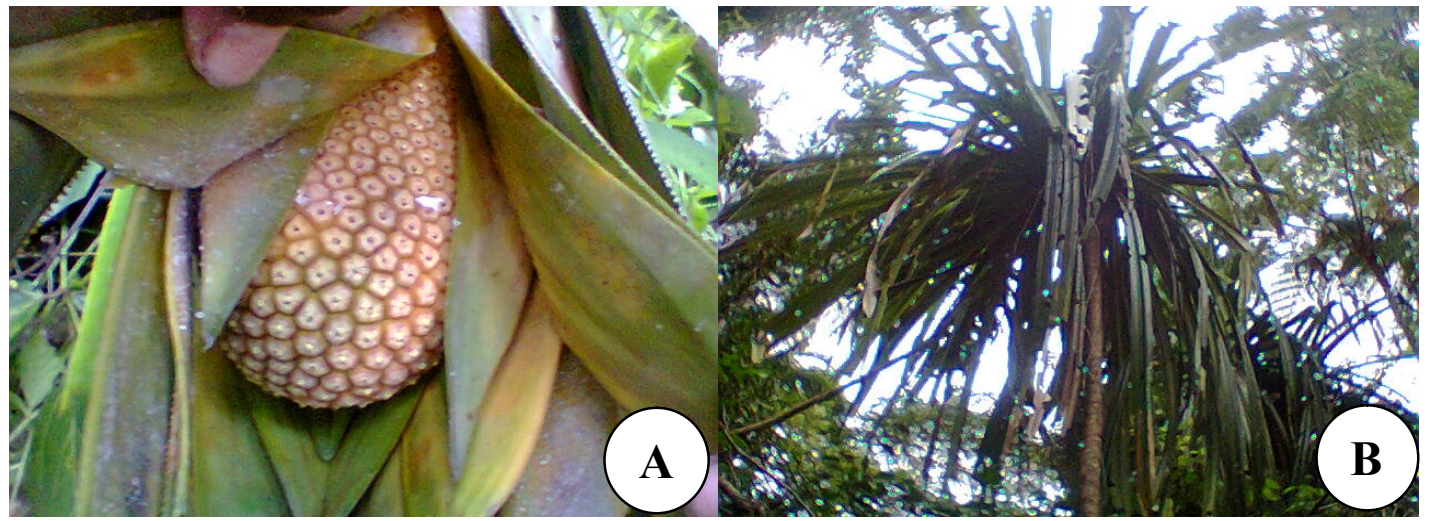

Gambar 2. Pandanus Kraneulianus. K. Sehum. A). buah dan B). Daun Pandanus kraneulianus. K. Sehum yang tumbuh di Kawasan Cagar Alam Biak Utara.

\section{Pandanus papuanus Solms. Laub Nama Daerah : Kakof}

Perawakan Pandanus berukuran sedang hingga besar, tumbuh tegak, berumpun hingga tunggal; Akar Warna akar Cokelat keabu - abuan bentuk akar tunjang, keadaan permukaan akar kasar dan berduri; Batang batang berbentuk bulat, warna cokelat keabu- abuan, diameter batang $13-17 \mathrm{~cm}$, tinggi pohon 6-8 $\mathrm{m}$, bentuk batang bulat dan arah tumbuh batang tegak, Daun bentuk ujung daun meruncing, susunan daun berseling pada batang, panjang daun $110-130 \mathrm{~cm}$, lebar daun $5-6,3 \mathrm{~cm}$, bentuk tepi dan bawah daun berduri, bentuk daun panjang, warna atas daun hijau mengkilat, sedangkan bagian bawah daun berwarna hijau keabu - abuan, jumlah daun 80-120 daun ; Bunga tidak ditemukan pada saat penelitian; Buah berbentuk bulat seperti buah durian, berwarna hijau saat muda dan, berwarna kuning saat matang; Habitat tumbuh pada tanah rawa sedikit berkapur dengan serasah tipis, tumbuh pada ketinggian $220 \mathrm{~m}$ dpl. Berasosiasi dengan Pakis, Palem, Ficus sp; Distribusi menyebar di daerah Papua, Papua Nugini, termasuk daerah Cagar Alam Biak Utara.

Spesimen Acuan : Cagar Alam Biak Utara, 30 April, 2015, MK.

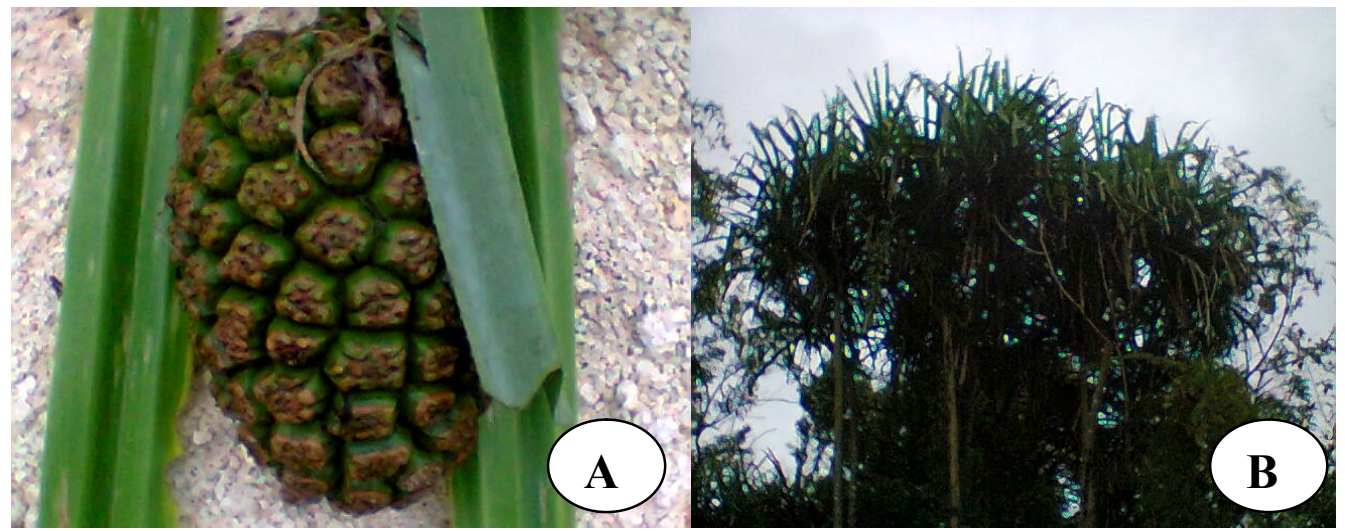

Gambar 3. Pandanus papuanus Solms.Laub. A. Daun dan B. Buah Pandanus papuanus Solms.Laub yang tumbuh di Kawasan Cagar Alam Biak Utara. 


\section{Pemanfaatan Pandanus Oleh Masyarakat di Sekitar Cagar Alam Biak Utara}

Masyarakat di sekitar Cagar Alam Biak Utara hanya memanfaatkan buah Pandanus sp sebagai bahan makanan, sedangkan bagian lain seperti daun, batang dan akar tidak dimanfaatkan. Apabila dibandingkan dengan daerah lain di Papua seperti masyarakat Tobati dan Enggros memanfaatkan akar Pandanus papuanus Solm sebagai bahan serat yang mengkilap dan kuat untuk jala dan tali pancing yang mampu bertahan hingga tiga tahun (Susiarti dkk. 2015).

Pemanfaatan Pandanus kraneulianus. K. Sehum oleh masyarakat di sekitar Cagar Alam Biak Utara tidak memanfaatkan buah sebagai bahan makan, tetapi bagian lain seperti daun sebagai anyaman atap pondok atau rumah dan batang untuk lantai rumah. Bila dibandingkan dengan daerah lain di luar Papua, masyarakat Halamahera mengkonsumsi buah jenis Pandanus tesebut sebagai bahan pangan (Susiarti dkk. 2015). Pemanfaatan Pandanus papuanus Solms oleh masyarakat di sekitar Cagar Alam Biak Utara sebagian yang dimanfaatkan dari Pandanus papuanus Solms, seperti batang Pandanus papuanus Solms digunakan sebagai bahan pembuatan lantai dan dinding pondok atau gubuk di kebun untuk beristirahat pada saat berkebun.

\section{Pembahasan Dan Tambahan Jenis Sararanga sp (Pandanaceae) Di Luar Kawasan Cagar Alam Biak Utara}

Marga Sararanga merupakan salah satu dari 3 (tiga) marga (Genus) dalam Suku (Famili) pandan-pandanan (Pandanaceae) - dua marga lainnya
Freycinetia dan Pandanus. Sampai saat ini diketahui hanya 2 (dua) jenis (species): Sararanga phillipinensis Merill dan Sararanga sinousa Hemsley. Kedua jenis tumbuhan ini tumbuh menyebar di daerah Papua dan Filipina (Heatubun 2005). Ditemukan 2 individu Sararanga sp. yang ditemukan ada 2 individu tumbuh di sekitar Kampung Korem, Distrik Biak Utara Kabupaten Biak Numfor. Deskripsi dari Sararanga sp. yang ditemukaan di Kampung Korem merupakan hasil pengamatan berdasarkan karakter morfologi yang dideskripsikan di bawah ini:

Deskripsi Jenis Sararanga sp: Tumbuhan tidak berkayu, umumnya sangat menyerupai tumbuhan pandan (pandanaceae) lainnya tidak berumpun, tinggi total dapat mencapai $18 \mathrm{~m}$. Batang: tumbuh tegak, berdiameter 15 $20 \mathrm{~cm}$, berwarna coklat muda keabu abuan dengan bercak-bercak kehitaman, pada pangkal batang tidak terdapat akar tunjang seperti pada umumnya jenis jenis pandan (pandanaceae) lainnya, biasanya beruas - ruas (berbuku), dengan panjang $10-15 \mathrm{~cm}$ dan tidak berduri. Umumnya bercabang dua, tiga dan empat atau kadang - kadang tidak bercabang (percabangan umumnya pada bagian ujung batang utama).

Daun: berbentuk pita, pedang atau garis berukuran $50-120 \mathrm{~cm} \times 5-15 \mathrm{~cm}$, bagian tepi dan kadang-kadang pada bagian punggung tulang daun berduri kecil - kecil yang tajam sama seperti tumbuhan pandan (pandanaceae) lainnya. Daun tersebar atau spiral, biasanya mengumpul pada ujung batang dan cabang. Bunga: biasanya terdapat pada ujung batang/cabang atau di ketiak daun, dengan daun pelindung yang besar, seringkali berwarna putih kekuningan 
atau kuning sampai orange, tetapi saat dilapangan tidak temukan bunga. Buah: berbentuk bulat lonjong yang umumnya agak melengkung seperti tanda bulan

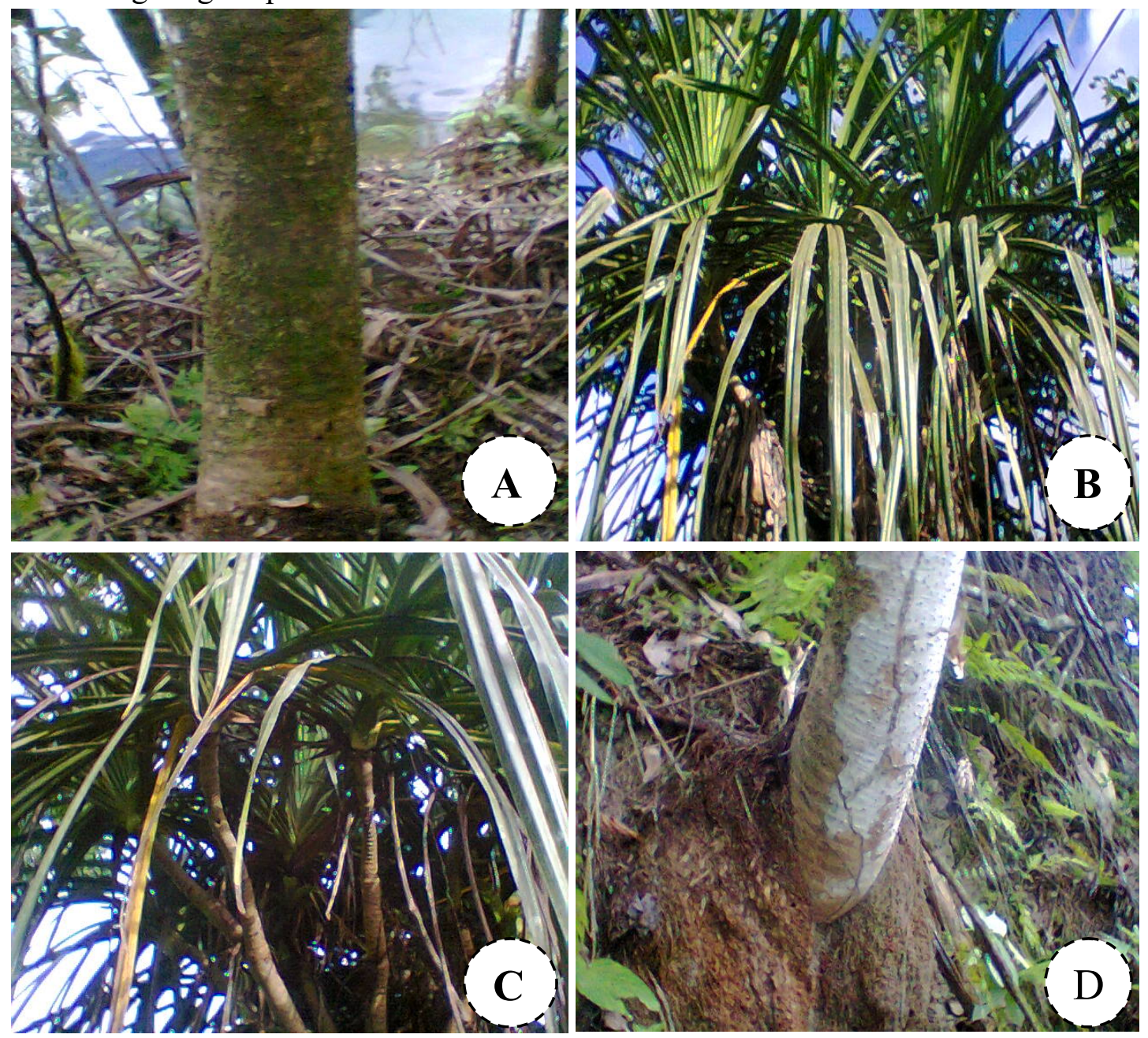

sabit, tetapi dilapangan tidak temukan buah. Biji: sangat kecil menyerupai biji rica, berjumlah sangat banyak.

Gambar 4. Karakteristik dan bentuk morfologi bantang (A). daun (B). daun (C). dan sistem perakaran (D). dari jenis pandanus.

\section{DAFTAR PUSTAKA}

Dahruddin H, Farida RW dan Rohman AS. 2005. Jenis-jenis tumbuhan Sumber pakan dan tempat bersarang kuskus (Famili Phalangeridae) di Cagar Alam Biak Utara, Papua. Bidang Zoologi, Pusat Penelitian Biologi, Lembaga Ilmu Pengetahuan 
Kemeray SB. 2013. Jenis - jenis Pandanus dan Freycinetia berdasarkan karakter morfologi dan anatomi di pulau Roswar kabupaten Teluk Wondama. Skripsi Sarjana Kehutanan, Fakultas Kehutanan Universitas Papua Manokwari.

Linda MS. 2012. Kawasan Konservasi di Indonesia

http://sonrain.blogspot.com/2012/03/k awasan-konservasi-ms-linda.html. Diakses Maret 2012.

Marpaung DRA, Pasaribu N dan Aththorick TA. 2013. Jurnal NaturalVol. 13, No. 2, 2013Taxonomic Study Of Pandanus (Pandanaceae)bIn Swamp Area, AcehSingkil.

http://jurnal.unsyiah.ac.id/natural/artic le/view/1216/1113.Mahasiswa
Pascasarjana Departemen Biologi, FMIPA, Universitas Sumatera Utara, Jl.Bioteknologi No. 1 Kampus USU Padang Bulan, Medan 20155. 2.

Sinaga NI, Pasaribu N dan Rifai MA.2011. Pandan-Pandanan (Pandanaceae). http://endangsusalni.blogspot.co $\mathrm{m} / 2011 / 07 /$ monocotyledoneae.

Htm. Diakses Juli 2011.

Stone BC. 1983. A guide to collecting Pandanaceae (Pandanus, Freycinetia, and Sararanga). Ann Missouri Bot Gard, 70(1): 137-145.

Susiarti S, Rahayu M dan Royyani MF. 2015. Pengetahuan dan pemanfaatan tumbuhan obat masyarakat Tobelo dalam di Maluku Utara. Media Litbangkes, Vol 25 (4): 211-218. 